Верещагин В. Ю., Верещагина А. С., Кравченко Е. Г.

V. Yu. Vereshchagin, A. S. Vereshchagina, E. G. Kravchenko

ТЕХНОЛОГИИ ДИАГНОСТИКИ СОСТОЯНИЯ РЕЖУЩЕГО ИНСТРУМЕНТА

НА СТАНКАХ С ЧИСЛОВЫМ ПРОГРАММНЫМ УПРАВЛЕНИЕМ

\title{
DIAGNOSTICS TECHNOLOGIES OF CUTTING TOOLS WITH CNC EQUIPMENT
}

Верещагин Владислав Юрьевич - студент кафедры «Технология машиностроения» Комсомольского-на-Амуре государственного технического университета (Россия, Комсомольск-на-Амуре). E-mail: Klirickv@gmail.com.

Mr. Vladislav Y. Vereshchagin - a student of Mechanical Engineering Department, Komsomolsk-on-Amur State Technical University (Russia, Komsomolsk-on-Amur). E-mail: Klirickv@gmail.com.

Верещагина Александра Сергеевна - кандидат технических наук, доцент кафедры «Технология машиностроения» Комсомольского-на-Амуре государственного технического университета (Россия, Комсомольск-на-Амуре). E-mail: osa321@gmail.com.

Ms. Alexandra S. Vereshchagina - PhD in Engineering, Assistant Professor, Mechanical Engineering Department, Komsomolsk-on-Amur State Technical University (Russia, Komsomolsk-on-Amur). E-mail: osa321@gmail.com.

Кравченко Елена Геннадьевна - кандидат технических наук, доцент кафедры «Технология машиностроения» Комсомольского-на-Амуре государственного технического университета (Россия, Комсомольск-на-Амуре). E-mail: ek74@ list.ru.

Ms. Elena G. Kravchenko - PhD in Engineering, Assistant Professor, Mechanical Engineering Department, Komsomolsk-on-Amur State Technical University (Russia, Komsomolsk-on-Amur). E-mail: ek74@list.ru.

Аннотация. Производительность современных автоматизированных станочных систем во многом зависит от состояния режущего инструмента. Фрезерование поверхностей является одной из наиболее сложных технологических операций при обработке металлов резанием. Отсутствие эффективных средств оперативной оценки износа фрезы вызывает ее поломку или снижение точности обработки, что приводит к браку и потере рабочего времени. В статье приведен обзор существующих методов диагностики состояния режущего инструмента.

Summary. Productivity of modern machine tools depends mostly on the cutting tool condition. One of the most complicated manufacturing process in metal cutting is a surface milling. The lack of effective tools for rapid assessment of cutter wear causes its damage or reduction in working accuracy, and leads to faulty production and the loss of working time. The article provides the overview of existing methods of the cutting tool diagnostics.

Ключевые слова: контроль износа режущего инструмента, диагностика состояния режущего инструмента, прямые методы, косвенные методы, виброакустические измерения, силовые измерения, виброакустическая эмиссия.

Keywords: cutting tool wear monitoring, diagnostics of the cutting tool, direct methods, indirect methods, vibro-acoustic measurement, power measurement, vibro-acoustic emission.

УДК 621.9 .02

В настоящее время актуальным становится вопрос о совершенствовании технологий диагностики состояния режущего инструмента на станках с ЧПУ.

По данным компании «Технология» [1] у большинства металлорежущих инструментов нарушения работоспособности при выполнении различных технологических операций 
Верещагин В. Ю., Верещагина А. С., Кравченко Е. Г.

ТЕХНОЛОГИИ ДИАГНОСТИКИ СОСТОЯНИЯ РЕЖУЩЕГО ИНСТРУМЕНТА НА СТАНКАХ С ЧИСЛОВЫМ ПРОГРАММНЫМ УПРАВЛЕНИЕМ

составляют сколы, отделение режущей части, поломки, выкрашивание и износ (рис. 1). При этом затраты времени на обнаружение и удаление вышедших из строя металлорежущих инструментов составляют около $10 \%$ от времени работы металлорежущих систем.

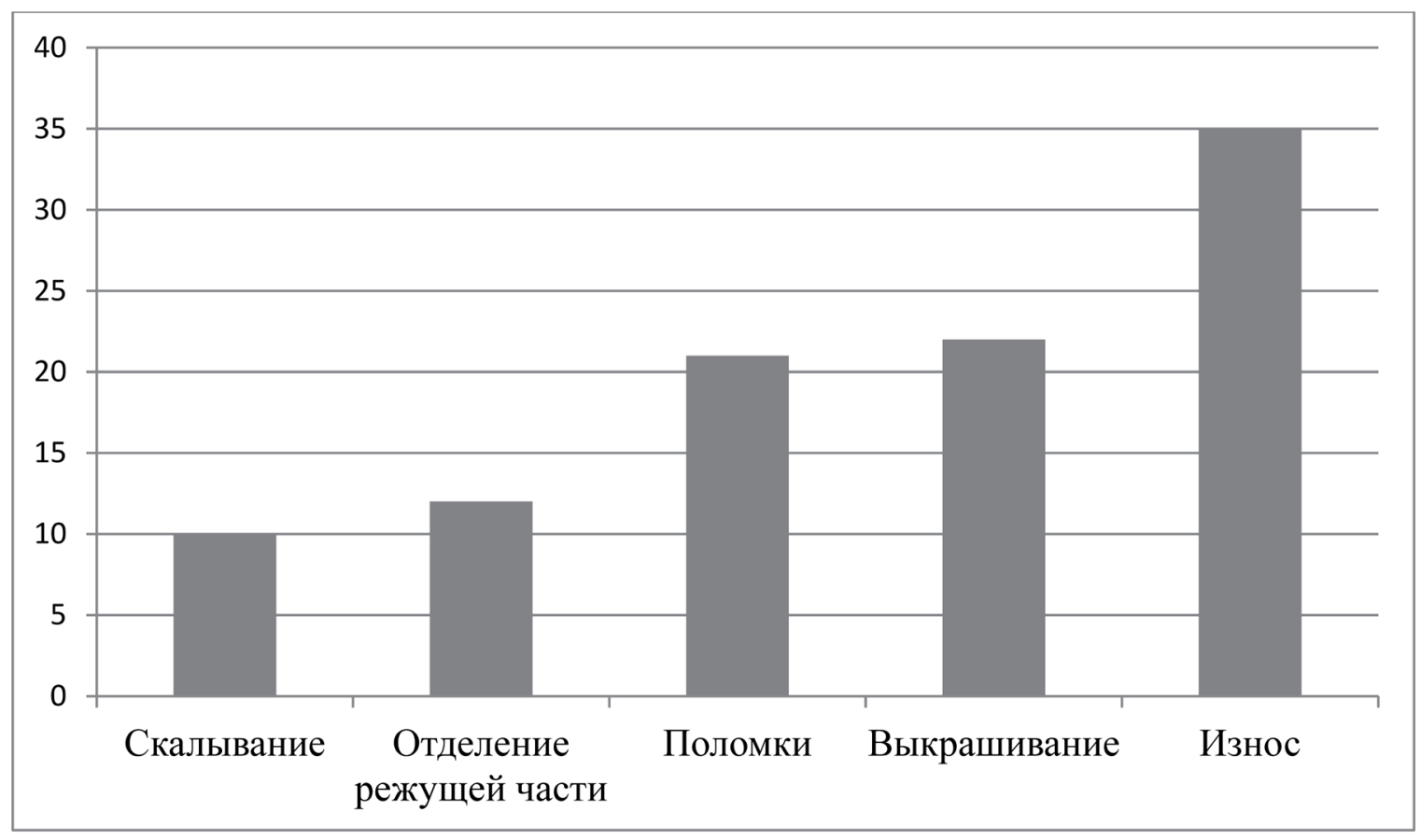

Рис. 1. Причины нарушения работоспособности инструмента

Таким образом, диагностирование износа режущего инструмента имеет большое значение для повышения надежности автоматизированного оборудования, а в частности - станков с ЧПУ.

В настоящее время существуют прямые и косвенные методы диагностики состояния режущего инструмента на станках с ЧПУ, объектами контроля которых служат режущий инструмент, обрабатываемая деталь, виды стружки, физико-механические параметры процесса резания. Контролируемыми параметрами являются износ инструмента, вибрации и температура в зоне резания, шероховатость обработанной поверхности, силы и мощность резания, ЭДС в зоне резания.

К прямым методам диагностики состояния инструмента относят:

- электромеханический;

- оптический;

- радиоактивный;

- пневматический;

- ультразвуковой.

К косвенным методам относят:

- измерение параметров заготовки (измерение габаритов, измерение шероховатости обработанной поверхности);

- измерение тепловых и электрических характеристик зоны резания (измерение температуры резания, измерение электрической проводимости контакта инструмент-деталь, измерение ЭДС резания);

- виброакустические измерения (измерение колебаний технологической системы, измерение амплитуд сигнала акустической эмиссии);

- силовые измерения (измерение составляющих силы резания, измерение крутящего момента, измерение мощности приводных электродвигателей). 
Прямые методы измерения параметров износа состояния режущего инструмента применяют непосредственно на самом инструменте, зачастую уже после остановки станка с ЧПУ или после выполнения операции по обработки детали. Прямые методы не позволяют оценить внутренние напряжения и деформации в материале, а также прогнозировать выход режущего инструмента из строя, поэтому их нельзя считать полноценными методами диагностики состояния режущего инструмента.

Большое количество исследований посвящено диагностике режущего инструмента косвенными методами. В литературе рассмотрен метод диагностирования режущего инструмента [2] и прогнозирование его остаточной стойкости в реальном времени, основанное на измерении составляющих сил резания. В работе решается задача непрерывного мониторинга диагностического признака, в качестве которого выступают составляющие силы резания. Координатные оси, по которым раскладывается сила резания, привязаны к механизмам, с помощью которых преодолевается сопротивление резанию.

Модель диагностирования (рис. 2) отражает состав и последовательность действий, необходимых для правильного сбора и обработки информации с датчиков, и последующего использования ее для диагностики состояния режущего инструмента.

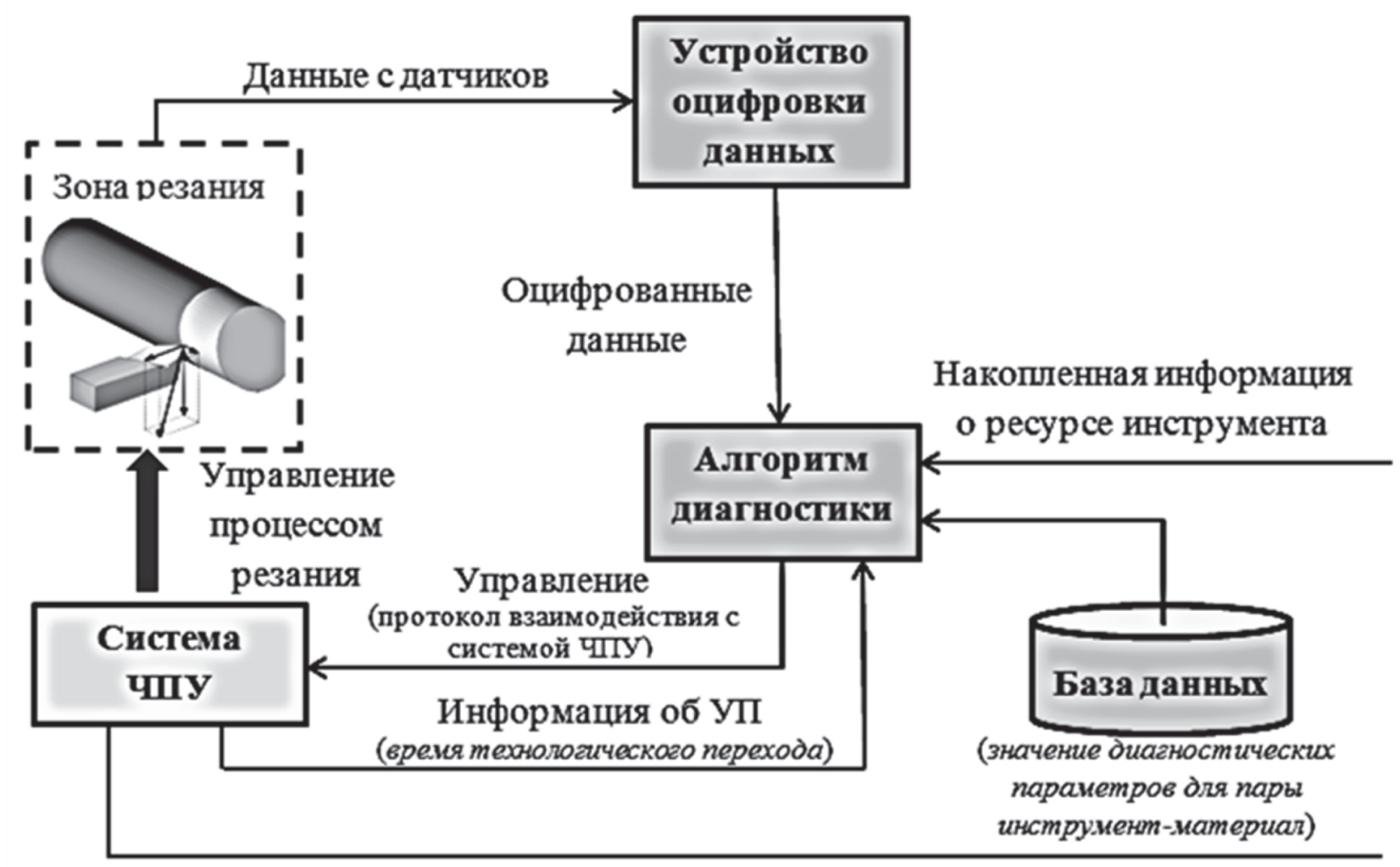

Рис. 2. Модель диагностирования и прогнозирования состояния режущего инструмента на станках с ЧПУ

На первом этапе происходит снятие измерительного сигнала из зоны резания с датчиков, косвенно характеризующих износ инструмента. На втором этапе происходит оцифровка и предварительная обработка измерительных сигналов. Измеренные данные подвергаются нормированию, усреднению и передаются в алгоритм диагностирования. На основании расчетов формируются управляющие сигналы, которые в дальнейшем подаются в систему ЧПУ.

Еще одним косвенным диагностическим признаком является уровень звука, генерируемого процессом резания, позволяющий прогнозировать момент замены режущего инструмента. В литературе рассмотрен виброакустический метод контроля состояния режущего ин- 
Верещагин В. Ю., Верещагина А. С., Кравченко Е. Г.

ТЕХНОЛОГИИ ДИАГНОСТИКИ СОСТОЯНИЯ РЕЖУЩЕГО ИНСТРУМЕНТА НА СТАНКАХ

С ЧИСЛОВЫМ ПРОГРАММНЫМ УПРАВЛЕНИЕМ

струмента на станках с ЧПУ [3], который предполагает правильный выбор рабочего частотного диапазона, т.е. диапазона, где наиболее видна зависимость амплитуды сигнала от износа режущего лезвия. В теории сделать такой выбор достаточно проблематичнно, т.к. весь частотный диапазон ограничивается возможностями современных датчиков вибраций, неинтеллектуализированных в достаточной степени и не оснащенных средствами самоконтроля [4].

Для определения в звуковом диапазоне полосы частот, наиболее информативной для диагностики износа, авторами работы была проведена серия экспериментов на станках с ЧПУ (при этом применялся широкополосный пьезоакселерометр АВС-27, установленный на торцевой части резца), получены виброакустические амплитудно-частотные характеристики режима резания в среде Audio-T [3]. В эксперименте в широких пределах изменялась глубина резания $t$, подача $S$ и число оборотов $n$, использовались заготовки из различных металлов с разными физико-механическими свойствами (сталь, латунь, дюралюминий).

Расчеты проводились с использованием эталонных значений, полученных ранее и сохраненных в базе данных. Сгенерированные алгоритмом диагностики сигналы поступают на выполнение в систему ЧПУ для управления исполнительными органами. Управляющими командами системы ЧПУ могут быть команда на подналадку станка, остановку, смену инструмента, команда на коррекцию режимов обработки.

Также еще одна система диагностики режущего инструмента была создана в инжиниринговом центре МГТУ «СТАНКИН» [5]. Система построена на основе вертикально-фрезерного станка с ЧПУ, оснащенного фрезерным динамометром и вибродатчиками (рис. 3).

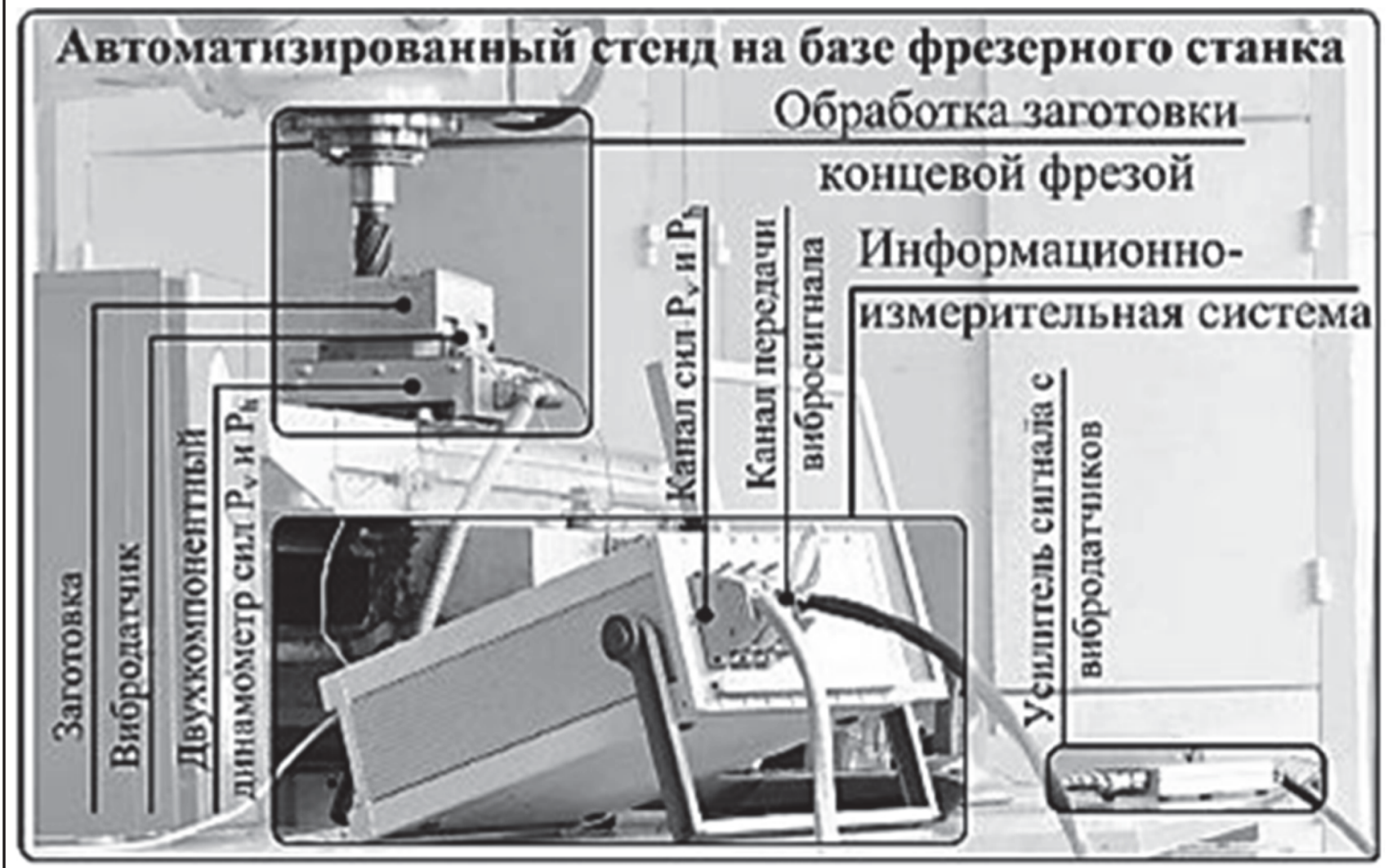

Рис. 3. Схема автоматизированного стенда, построенного на базе фрезерного трехкоординатного станка с ЧПУ

Предложенная схема автоматизированного стенда содержит следующие компоненты:

- исполнительную систему (фрезерный трехкоординатный станок с ЧПУ). Служит для обработки материалов резанием по заданным режимам; 
- систему адаптивного управления по силе резания и уровню вибрации для регистрации составляющих силы резания, виброускорения и формирования управляющего сигнала;

- систему износа инструмента, которая предназначена для получения и анализа трехмерного изображения инструмента и оценки его износа в режиме «off-line»;

- систему согласования сигналов;

- систему сбора и передачи измерительной информации;

- систему хранения и отображения измерительной информации;

- систему обработки измерительной информации;

- систему связи и передачи данных, предназначенную для обеспечения связи между системами.

Можно сделать вывод о том, что в современных системах диагностирования режущего инструмента применяются информационные системы, включающие:

- систему сбора данных (различные виды датчиков: виброакустические, силовые, тепловые);

- устройство оцифровки данных;

- алгоритмы диагностики;

- базы данных с эталонными значениями измерительной информации;

- систему обратной связи со станком с ЧПУ, которая позволяет в автономном режиме управлять процессами резания и вносить корректировки, если потребуется.

Управление информационной системой диагностирования режущего инструмента в целом происходит под контролем ЭВМ. Также хотелось отметить, что диагностировать состояние режущего инструмента на станках с ЧПУ целесообразно не каждым методом отдельно, а использовать их синтез, например, одновременно использовать виброакустические и силовые методы контроля. Это повысит их точность и поможет более эффективно прогнозировать состояние режущего инструмента в процессе обработки.

\section{ЛИТЕРАТУРА}

1. Компания «Технология»: [Электронный ресурc]. URL:

http://texnologia.ru/documentation/cutting_of_metals/7.html (Дата обращения 26.12.2015).

2. Григорьев, А. С. Диагностирование резцов и прогнозирование их остаточной стойкости в реальном времени обработки на основе создания инструментария системы ЧПУ: автореф. дис. ... канд. тех. наук. - М., 2012. - 17 C.

3. Добровинский, И. Р. К вопросу контроля состояния режущей кромки резца виброакустическим методом / И. Р. Добровинский, Ю. Т. Медведик, М. Ю. Медведик // Известия высших учебных заведений. Поволжский регион. Технические науки. - 2014. - № 3(31). - С. 102-116.

4. Шаблицкий, А. Ю. Метрологический самоконтроль в интеллектуальном акустическом пьезоэлектрическом датчике / А. Ю. Шаблицкий, В. К. Доля // Известия высших учебных заведений. Поволжский регион. Технические науки. - 2012. - № 3(23). - С. 36-45.

5. Измерение износа резца виброакустическим методом и моделирование напряженности акустического поля внутри режущего инструмента / И. Р. Добровинский [и др.] // Известия высших учебных заведений. Поволжский регион. Технические науки. - 2013. - № 2(26). - С. 59-70.

6. Порватов, А. Н. Аппаратно-программный комплекс для диагностирования состояния и повышения эксплуатационной надежности технологическим систем / А. Н. Порватов, А. А. Туманов // Вестник МГТУ «Станкин» . - 2013. - №1(24). - С. 89-91. 